\title{
Determinants of Affective Factors in Mathematics Achievement: Structural Equation Modeling Approach
}

\author{
Myint Swe Khine (Corresponding author) \\ Emirates College for Advanced Education \\ United Arab Emirates \\ E-mail: mskhine@ecae.ac.ae / dr.mkhine@gmail.com
}

Masooma Al-Mutawah

University of Bahrain

Kingdom of Bahrain

Ernest Afari

Petroleum Institute

United Arab Emirates

Received: April 11, 2015 Accepted: May 14, 2015 Published: May 14, 2015

doi:10.5296/jse.v5i2.7484 URL: http://dx.doi.org/10.5296/jse.v5i2.7484

\begin{abstract}
The study on attitudes towards learning has a long tradition in mathematics education. While attitude as a construct has been investigated from different aspects, the researchers recognized that attitude encompasses many other related factors. This paper describes the affective factors that form attitudes and their important role in mathematics achievement. The affective factors identified in this study are students liking, value and confident in learning mathematics. The 20-item self-report survey adapted from TIMSS 2011 context questionnaire was translated into Arabic and administered to 387 students in schools in a Gulf state. The data was analyzed with structural equation modeling software. The results show that affective factors significantly and positively influence students' mathematics achievement in this context.
\end{abstract}

Keywords: TIMSS, Attitudes, Affective factors, Achievement, Structural equation modeling 


\section{Introduction}

In improving mathematics education, researchers recognized that attitude, belief, interest and other affective variables play a key role in students' achievement. The study on attitudes had a long history in education and social sciences and different conceptual frameworks, theoretical perspectives and measurements were suggested by educators, psychologists and sociologists (Chaman et al, 2014; Lomas et al, 2012; Cretchley, 2008). However attitude research faced uncertainty due to diverse interpretation including its constituents and host of other factors that made up the construct (Khine and Afari, 2014). Zan and Di Martino (2007) also urged that there is a lack of theoretical clarity in research on attitude.

\section{Attitudes and achievement}

Possible relationships and associations between attitudes towards mathematics and achievement outcomes were studied extensively in the past. When Lim and Chapman (2013a) studied attitudes toward mathematics, they considered enjoyment of mathematics, self-confidence in mathematics and perceived value of mathematics as sub-constructs of attitude. The study found significant correlations between enjoyment, self-confidence and value and the concurrent and predictive mathematics achievement test scores. The study noted that the variance accounted for by these attitudes sub-constructs towards achievement scores are $34 \%$ for male and $24 \%$ for female respectively. Hannula (2002) had an opinion that "Attitude is not seen as a unitary psychological construct, but as a category of behavior that is produced by different evaluative process. Students may express liking or disliking of mathematics because of emotions, expectations and values (p.30)".

In their study, Ing and Nylund-Gibson (2013) identified mathematics and science attitudes constructs based on social cognitive career theory. These being self-efficacy, outcome expectations, interest and goal. They found significant differences in the mathematics score and attitudes variables. In other studies, an attitude towards mathematics is defined as "an aggregated measure of liking and disliking of mathematics, a tendency to avoid or engage mathematical activities and a belief that mathematics is useful or useless (Ma \& Kishor, 1997, p. 27).

In search of the definition of the mathematics attitudes, Di Martino and Zan (2010) proposed a three dimensional model for attitude (TMA) that shows interconnections between emotional dispositions towards mathematics, vision of mathematics and perceived competence in mathematics. Di Martino and Zan (2015) again noted that the TMA model originally created as model for students' attitudes towards mathematics is also applicable in examining attitude towards specific mathematics topic. They suggested that the development of research on attitudes need to explore constructing new observational tools and identifying possible motives behind the change of attitude.

The study by Lipnevich et al (2011) stressed the importance of attitude towards mathematics that predict achievement outcomes among students. The results for their study showed that attitudes explained variance of $25 \%$ to $32 \%$ in the mathematics achievement. In the study conducted by Mata et al (2012) with 1719 Portuguese students, from fifth-to-twelfth grade 
using "In my Math Class" inventory, they found that motivation related variables are the main predictors of attitudes towards mathematics and that teachers and the social support of peers are also highly significant in understanding these attitudes.

Hemming et al (2011) examined the relationships among attitude towards mathematics, ability and mathematical achievement with Australian secondary school students and found that females were more likely to hold more positive attitudes towards mathematics. The analysis also showed that ability as measured by standardized test results in numeracy and literacy and attitude towards mathematics played a role in explaining mathematical achievement in secondary school. They concluded that "ability and attitude work in tandem to explain mathematical success" (p. 702). According to Atweh and Brady (2009) students are more likely to continue to study mathematics and put greater effort in learning mathematics if their perceived value of mathematics is relevant to their life and future carriers. Hannula (2012) further identified that values are part of the motivational dimension.

The relationship between attitudes towards mathematics self-efficacy and achievement in problem-solving was explored by Nicolaidou el al (2003) with 238 fifth-grade pupils in Cyprus. The study found the significant relationship between attitudes and achievement and a stronger relationship between efficacy and achievement. It was also found that attitudes and efficacy predicted achievement in problem-solving. Dogan (2012) noted the emotion, confidence and perception of mathematics among students and the role of active learning environment. The study reported that active learning environment changed students' emotion, confidence and perceptions about mathematics learning.

In a study by Parsons' et al (2009), they detected statistically significant relationship between students' confidence in mathematics and achievement in mathematics. The results from the questionnaire eliciting information about confidence in mathematics and GCSE mathematics grades were found to be significantly correlated among 111 first year university students. Similarly the study found that liking of mathematics was correlated to the mathematics achievement. When identifying affective domains that correlate and predict mathematics performance among students in Singapore, Lim and Chapman (2013b) reported that among affective variables, self-confidence in mathematics and perceived value of mathematics were found to be correlated with mathematics achievement. Stankov et al (2014) also noted the importance of confidence as a predictor of academic achievement. From these literatures it can be construed that students liking of learning mathematics, value learning mathematics and confidence in learning mathematics are some of the affective factors to consider in predicting students achievements.

\section{Research questions}

The study attempted to examine the relationships between affective factors specifically students' liking mathematics, students' value learning mathematics and students' confident learning mathematics and mathematics achievement. The hypothesized model developed to test the relationships of the constructs is as follows: 


\section{Macrothink}

Journal of Studies in Education

ISSN 2162-6952

2015, Vol. 5, No. 2

1. Students' like learning mathematics has a significant positive effect on mathematics achievement

2. Students' value learning mathematics has a significant positive effect on mathematics achievement

3. Students' confidence in learning mathematics has a significant positive effect on mathematics achievement

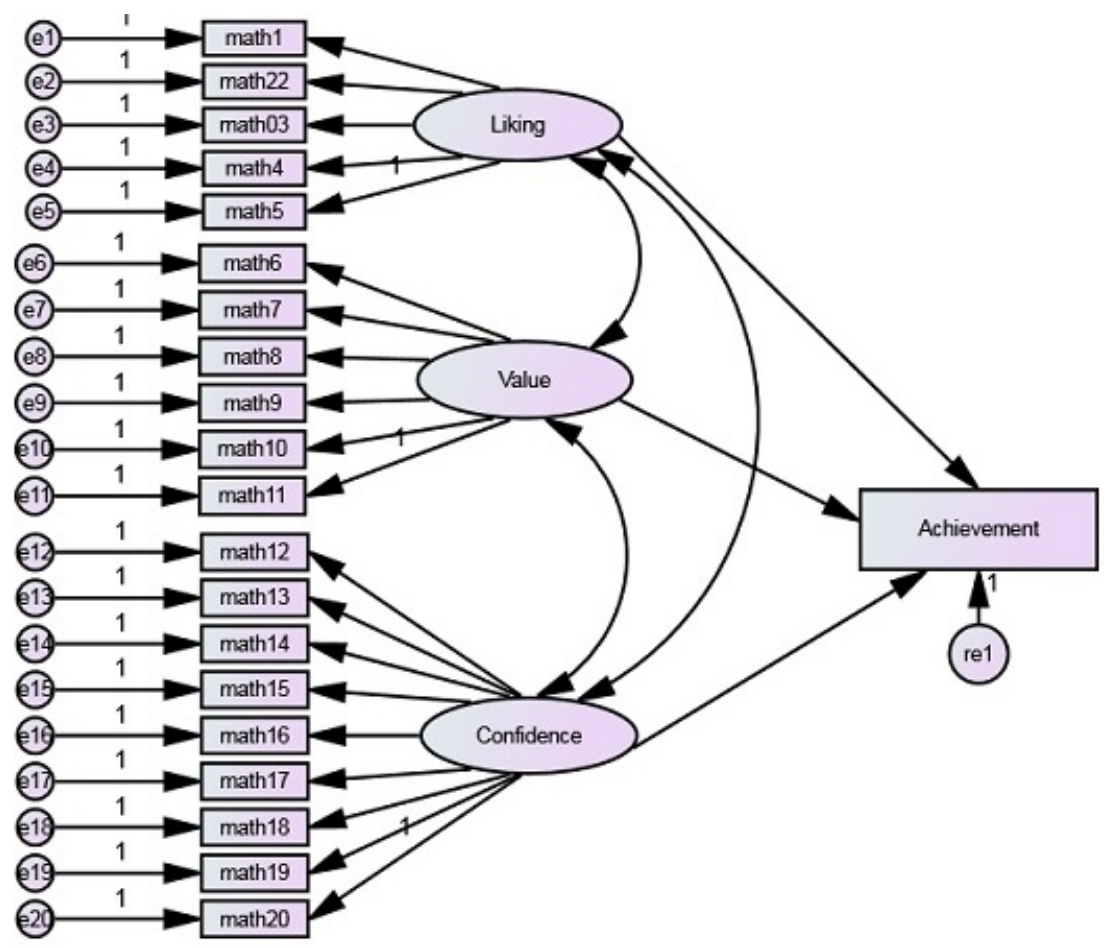

Figure 1. Hypothesized model of the relationship between attitudes towards mathematics and achievement.

\section{Research methodology}

The study aims to determine the reliability and validity of the instrument and relationships between the affective factors and students' achievement in mathematics. Participants in this study were 387 students randomly selected from three high schools in a Gulf state. 200 students were male and 187 students were female. The data was collected with the use of 20 items questionnaire accessing the students' affective factors namely students like learning mathematics, students value mathematics and students confident in mathematics. These three constructs were adapted from TIMSS 2011 contextual questionnaire (Martin et al, 2011).

Student like learning mathematics scale was accessed by five items and examples of items are read "I enjoy learning mathematics" and "I learn many interesting things in mathematics". Similarly the students' value mathematics was assessed by six items and a sample item reads "I think learning mathematics will help me in my daily life". The student confident in mathematics scale was assessed by nine items and these include "I usually do well in mathematics" and "My teacher tells me I am good at science". Not all items are positively 
worded and some of them are negatively worded to ensure the reliability. Students respond to the question items on 5-point Likert type scale ranging from strongly agree and strongly disagree. The original items in English were translated into Arabic and a panel of experts examined the face validity of the question items and made some adjustments to suit the language level of the students.

The data were analyzed using structural equation modeling (SEM) approach with AMOS 22 software. In the first step to determine the internal consistency and reliability of the items, Cronbach alpha was computed for all three scales. Following the reliability test, confirmatory factor analysis was conducted to examine the factor structure. The overall model fit was assessed with common absolute fit indices. The measurement of fit indices comprises Chi-square, Turker-Lewis index (TLI), comparative fit index (CFI), incremental fit index (IFI), root mean square error of approximation (RMSEA) and Standardized root mean square residual (SRMR).

\section{Results}

The following section presents the proposed structural model, descriptive statistics, tests of reliability, convergent validity, and discriminant validity, test of the measurement model, and test of hypothesis and finding from the analysis.

The research model presented in Figure 1 hypothesizes that each of the three constructs of mathematical attitudes (students liking mathematics, students' value of mathematics and students confident in mathematics) has a relationship with mathematics achievement.

The means, standard deviations, skewness and kurtosis values of the constructs (liking, value, confident) are shown in Table 1. The mean scores range from 3.01 to 3.86, indicating that the students who participated in the study exhibited a strong response to the factors that are measured in this study. The standard deviations indicate that the item scores were narrowly spread around the mean. The skewness and kurtosis values indicate that respective distributions of each subscale do not differ substantially from a normal distribution (Tabacknick \& Fidell, 2013). Therefore univariate normality was supported in the items.

A requirement of SEM analyses is the assumption that the data are multivariate normal (McDonald \& Ho, 2002). In our study, the multivariate normality of the data was evaluated using Mardia's (1970) multivariate skewness and kurtosis coefficient. The value of the Mardia's coefficient obtained in this study, using AMOS 22, was 94.23. As suggested by Raykov \& Marcoulides, 2008, this value was less than $p(p+2)$ where $p=$ total number of observed indicators; $20(22)=440$. The requirement of multivariate normality was therefore satisfied and the data considered normal for SEM.

Analyses were conducted to determine the consistency of the items. The resulting Cronbach alpha value for the Mathematics attitude scale (20-items) was .93. The Cronbach alpha coefficients for the factors (Liking, Value and Confidence) were .87, .82, and .89, respectively. Cronbach alpha values for all the factors were above .80 , suggesting adequate internal consistency of the questionnaires (Nunnally and Bernstein, 1994). 
Table 1. Mean, standard deviation, skewness and kurtosis of the items

\begin{tabular}{|c|c|c|c|c|c|}
\hline & Item & Mean & SD & Skewness & Kurtosis \\
\hline \multicolumn{6}{|c|}{ Liking } \\
\hline 1. & I enjoyed learning mathematics. & 3.17 & .99 & -1.02 & -.03 \\
\hline 2. & I wish I did not have to study mathematics. & 3.75 & 1.20 & -.31 & -1.46 \\
\hline 3. & Mathematics is boring. & 3.86 & 1.12 & -.43 & -1.23 \\
\hline 4. & I learn many interesting things in mathematics. & 3.01 & 1.05 & -.66 & -.83 \\
\hline \multirow[t]{2}{*}{5.} & I like mathematics. & 3.15 & 1.11 & -.72 & -.89 \\
\hline & Value & & & & \\
\hline 6. & $\begin{array}{l}\text { I think learning mathematics will help me in my daily. } \\
\text { life. }\end{array}$ & 3.01 & 1.06 & -.78 & -.65 \\
\hline 7. & I need mathematics to learn other school subjects. & 3.03 & 1.00 & -.56 & -.78 \\
\hline 8. & $\begin{array}{l}\text { I need to do well in mathematics to get into the } \\
\text { university. }\end{array}$ & 3.52 & .77 & -1.73 & 2.59 \\
\hline 9. & I need to do well in mathematics to get the job I want. & 3.25 & .95 & -1.06 & .04 \\
\hline 10. & I would like a job at involves using mathematics. & 3.63 & 1.11 & -.18 & -1.31 \\
\hline 11. & It is important to do well in mathematics. & 3.54 & .77 & -1.75 & 2.53 \\
\hline
\end{tabular}

\section{Confident}

12. I usually do well in mathematics.

3.26

.84

$-.99$

.34

13. Mathematics is more difficult for me than for many of my

3.99

1.03

$-.58$

$-.92$ classmates.

14. Mathematics is not one of my strength.

3.70

1.09

$-.18$

$-1.30$

15. I learn things quickly in mathematics.

3.10

3.60

.93

$-.80$

$-.26$

16. Mathematics makes me confused and nervous.

1.07

$-.05$

$-1.27$

17. I am good at working out difficult mathematics problems.

3.08

1.00

$-.31$

$-.94$

18. My teacher thinks I can do well in mathematics.

$\begin{array}{lccc}3.51 & .75 & -1.48 & 1.56 \\ 3.40 & .85 & -1.37 & 1.10 \\ 3.98 & 1.12 & -.65 & -1.02\end{array}$

20. Mathematics is harder for me than any other subject 


\section{Ml Macrothink}

The 20 items of the mathematics attitude instrument were tested for convergent validity by determining item loadings, composite reliability and average variance extracted (AVE; Fornell \& Larcker, 1981). The minimum requirement suggested for item loadings is .7 (Barclay, Higgins \& Thompson, 1995; Chin, 1998; Hair et al., 2010; Hulland, 1999), composite reliability is .7 (Nunnally \& Bernstein, 1994), and AVE is .5 (Fornell \& Larcker, 1981). The item loadings, composite reliability and the average variance extracted are reported in Table 2.

Table 2. Item loadings, composite variance, average variance extracted and communalities

\begin{tabular}{|c|c|c|c|c|c|}
\hline Latent Variable & Item & $\begin{array}{c}\text { Item } \\
\text { loading }\end{array}$ & $\begin{array}{l}\text { Average Variance } \\
\text { Extracted (AVE) }\end{array}$ & $\begin{array}{c}\text { Composite } \\
\text { Reliability (CR) }\end{array}$ & Communalities \\
\hline & math1 & .91 & & & .71 \\
\hline & math2 & .72 & & & .47 \\
\hline & math3 & .80 & .59 & .88 & .71 \\
\hline \multirow[t]{4}{*}{ Liking } & math4 & .50 & & & .66 \\
\hline & math5 & .85 & & & .78 \\
\hline & math6 & .77 & & & .53 \\
\hline & math7 & .84 & & & .54 \\
\hline \multirow[t]{8}{*}{ Value } & math 8 & .64 & .55 & .88 & .77 \\
\hline & math9 & .75 & & & .83 \\
\hline & math10 & .78 & & & .63 \\
\hline & math11 & .67 & & & .46 \\
\hline & math12 & .74 & & & .58 \\
\hline & math13 & .73 & & & .69 \\
\hline & math14 & .67 & & & .58 \\
\hline & math15 & .76 & .54 & .91 & .64 \\
\hline \multirow[t]{5}{*}{ Confidence } & math16 & .80 & & & .63 \\
\hline & math17 & .81 & & & .60 \\
\hline & math18 & .73 & & & .76 \\
\hline & math19 & .65 & & & .79 \\
\hline & math20 & .73 & & & .73 \\
\hline
\end{tabular}

The results indicate that all item loadings were found to be above the recommended cut-off point, except for items math4, math8, math11, math14 and math19. The communalities of these items (Table 2) were more than .3, indicating that all these items fit well with the other items in the factors. We therefore decided to include all the items for further analysis.

Composite reliability was obtained for each construct, and the results (Table 2) show that all three constructs met the suggested minimum value of .7. The final criterion to satisfy convergent validity was the measure of the AVE for each factor. Results of the analysis (Table 2) showed that the AVE values for all the scales were above .50. Therefore, the 
measurement properties satisfied all three necessary criteria of convergent validity. Hence, the results indicated that the items in each construct were highly correlated and reliable.

The criterion of discriminant validity was that the square root of AVE for each construct is larger than the inter-construct correlation. The results in Table 3 support the discriminant validity because, for each construct, the square root of the AVE for each construct was larger than its correlation with other constructs. The result confirms that discriminant validity was achieved. The discriminant validity analyses ensured that the individual constructs in the questionnaire were discriminated from each other.

Table 3. Inter-Construct Correlations and Square Root of Average Variance Extracted

\begin{tabular}{lccc}
\hline Constructs & Liking & Value & Confidence \\
Liking & $\mathbf{( . 7 7 )}$ & & \\
Value & $.64^{* *}$ & $\mathbf{( . 7 4 )}$ & \\
Confidence & $.71^{* *}$ & $.58^{* *}$ & $\mathbf{( . 7 3 )}$ \\
\hline
\end{tabular}

$*^{*} p<.01$ : The elements in bold and parentheses in the main diagonal are the square roots of average variance extracted.

The research model in Figure 1 was tested using the SEM approach, using AMOS 22.0 (Arbuckle, 2012). Table 4 summarizes the commonly used measures of model fit based on results from an analysis of the structural model, the recommended level of acceptable fit, and the fit indices for the research model in this study. All of the values satisfied the recommended level of acceptable fit with the exception of the $\chi^{2}$. Hair et al. (2010) noted that, as the sample size increases, there is a tendency for the $\chi^{2}$ to indicate significant differences. For this reason, the ratio of $\chi^{2}$ to its degrees of freedom $\left(\chi^{2} / \mathrm{df}\right)$ was used, with a ratio of 5 or less being indicative of an acceptable fit between the hypothetical model and the sample data. The results of the model fit, as shown by the various fit indices in Table 4, indicate that the research model fits the data fairly well.

Table 4. Fit Indices for the Research Model

\begin{tabular}{ccc}
\hline Model fit indices & Values & Recommended guidelines \\
\hline$\chi^{2}$ & $352.82, \quad p<.001$ & Nonsignificant \\
$\chi^{2} / \mathrm{df}$ & 2.09 & $<5$ \\
TLI & .95 & $\geq .90$ \\
CFI & .96 & $\geq .90$ \\
IFI & .96 & $\geq .90$ \\
RMSEA & .05 & $<.08$ (adequate fit) \\
SRMR & .04 & $<.05$ \\
\hline
\end{tabular}

*Hair et al. (2010)

The path coefficients and $t$-value for each of the hypothesized relationships in the model are reported in Table 5.It was found that confidence had a positive impact on students' academic achievement. Confidence was positively and significantly related to achievement $(\beta=.62, p$ $<.001)$, whereas, liking and value were not significantly related to achievement $(\beta=.126, p$ $<.47 ; \beta=-.16, p<.35)$. One endogenous variable was tested in the model. Achievement was 
found to be significantly determined by confidence, resulting in an $R^{2}$ of .36 . This means that confidence explained $36 \%$ of the variance in achievement.

Table 5. Hypothesis Testing Results

\begin{tabular}{lcc}
\hline \multicolumn{1}{c}{ Path } & Path coefficient & $t$ \\
\hline Liking $\rightarrow$ Achievement & .126 & .72 \\
Value $\rightarrow$ Achievement & -.16 & -.94 \\
Confidence $\rightarrow$ Achievement & .62 & $4.87^{* * *}$ \\
\hline$* * * p<.001$ & &
\end{tabular}

\section{Associations between Students' Attitude to Mathematics and achievement}

Associations between students' attitude to mathematics and academic achievement were investigated using Pearson's product-moment correlation coefficient. As mentioned previously, a three-factor instrument (students liking mathematics, students' value of mathematics and students confident in mathematics), was used to measure students' attitudes to mathematics. The end of year mathematics examination scores for 387 students was used to measure academic achievement.

As suggested by Cohen (1988), the correlation coefficient with values $r=.10$ to .29 were considered small, values between $\mathrm{r}=.30$ and .49 , inclusive were considered medium, and values of $\mathrm{r}=.50$ to 1.00 were considered large. There was strong positive correlation between confidence and achievement $(\mathrm{r}=.58, \mathrm{n}=387, p<.01)$. Also, there were medium positive correlations' between liking and achievement $(\mathrm{r}=.48, \mathrm{n}=387, p<.01)$ and value and achievement $(\mathrm{r}=.33, \mathrm{n}=387, p<.01)$. This suggest that attitude to mathematics might have a relationship with mathematics achievements, and that those students who exhibit positive attitude to mathematics are more likely to perform well in mathematics. The correlations are displayed in Table 6.

Table 6. Pearson correlations between mathematics achievement and attitude scales

\begin{tabular}{lc}
\hline Mathematics Attitude Scale & Mathematics achievement \\
\hline Liking & $.48^{* *}$ \\
Value & $.33^{* *}$ \\
Confidence & $.57^{* *}$ \\
\hline
\end{tabular}

Note. $* * p<.01$

\section{Discussion and conclusion}

The study investigated the effect of affective factors in mathematics learning and mathematics achievement among high school students in a Gulf state. The results of this study show that students liking mathematics learning has a positive relationship with mathematics achievement. Similarly students' perception of the value of mathematics learning has a positive relationship with mathematics learning. It was also found that students' confidence in mathematics learning has a positive association with mathematics learning. All effects are found to be statistically significant and in agreement with other findings in the literature. 


\section{Al Macrothink}

Journal of Studies in Education

ISSN 2162-6952

2015, Vol. 5, No. 2

The results of this study present both theoretical contribution and practical implications. The results show that students' confidence is predictor of their achievement. The evidence from other studies suggests that it is necessary to take a closer look at mathematics classrooms and how the students are progressing (Zan et al, 2006; Di Martino \& Zan, 2011). Recent findings portray that traditional curriculum and instruction are not serving students well. Due to lack of creativity and innovative methods, students are not taking serious interest in the subject. In order to increase students' interest and motivate them to learn mathematics, students should be engaged with real-world issues and encouraged to have discussions about mathematical thinking (Fernandez et al, 2012). In addition, group work and collaborative problem solving will improve the attitudes of the students. Teachers should help students to build a foundation of mathematical concepts and skills and to develop positive attitudes towards the subject. Such new pedagogies may include constructivist and participatory approaches to learning, using technology, innovative and creative methods in active learning to help improve students' attitudes towards mathematics and gain confidence in solving mathematical problems.

\section{References}

Arbuckle, J. L. (2012). Amos [Computer software]. Chicago, IL: SPSS.

Atweh, B., \& Brady, K. (2009). Socially response-able mathematics education: Implications of an ethical approach. Eurasia Journal of mathematics, science \& technology education, 5(3), 267-276.

Barclay, D., Higgins, C., \& Thompson, R. (1995). The Partial Least Squares (PLS) approach to causal modeling: Personal computer adoption and uses as an illustration. Technology Studies, 2, 285-309.

Chaman, M. J., Beswick, K., \& Callingham, R. (2014). Factors Influencing Mathematics Achievement among Secondary School Students. In The Future of Educational Research (pp. 227-238). Sense Publishers. http://dx.doi.org/10.1007/978-94-6209-512-0_19

Chin, W.W. (1998). Issues and opinion on structural equation modeling.MIS Quarterly, 22, vii-Xvi.

Cohen, J. (1988). Statistical power analysis for the behavioral sciences. Hillsdale, NJ: Routledge. http://dx.doi.org/10.1002/bs.3830330104

Cretchley, P. (2008). Advancing research into affective factors in mathematics learning: Clarifying key factors, terminology and measurement. In Navigating currents and charting directions: Proceedings of the $31^{\text {st }}$ Annual conference of Mathematics Education Research of Australasia (pp. 147-154).

Di Martino, P., \& Zan, R. (2010). 'Me and maths': towards a definition of attitude grounded on students' narratives. Journal of Mathematics Teacher Education, 13, 27-48. http://dx.doi.org/10.1007/s10857-009-9134-z 
Di Martino, P., \& Zan, R. (2011). Attitude towards mathematics: a bridge between beliefs and emotions. ZDM, 43(4), 471-482. http://dx.doi.org/10.1007/s11858-011-0309-6

Di Martino, P., \& Zan, R. (2015). The Construct of Attitude in Mathematics Education. In B. Pepin \& B. Roesken-Winter (Eds.) From beliefs to dynamic affect systems in mathematics education (pp. 51-72). Springer International Publishing. http://dx.doi.org/10.1007/978-3-319-06808-4_3

Dogan, H. (2012). Emotion, confidence, perception and expectation case of mathematics. International Journal of Science and Mathematics Education, 10(1), 49-69. http://dx.doi.org/10.1007/s10763-011-9277-0

Fernández, C., Llinares, S., \& Valls, J. (2012). Learning to notice students' mathematical $\begin{array}{llll}\text { thinking through on-line discussions. } & Z D M, & 44(6),\end{array}$ http://dx.doi.org/10.1007/s11858-012-0425-y

Fornell, C., \& Larker, D. F. (1981).Evaluating structural equation models with unobservable variables and measurement error. Journal of Marketing Research, 18, 39-50. http://dx.doi.org/10.2307/3150980

Hannula, M. S. (2002). Attitude towards mathematics: Emotions, expectations and values. Educational studies in Mathematics, 25-46. http://dx.doi.org/10.1023/A:1016048823497

Hannula, M. S. (2012). Looking at the third wave from the West: framing values within a broader scope of affective traits. ZDM, 44(1), 83-90. http://dx.doi.org/10.1007/s11858-012-0410-5

Hair, J., Black, W., Babin, B., \& Anderson, R. (2010). Multivariate Data Analysis (7th Edition). Upper Saddle River, New Jersey: Prentice-Hall. http://dx.doi.org/10.1016/j.jmva.2009.12.014

Hemmings, B., Grootenboer, P., \& Kay, R. (2011). Predicting mathematics achievement: The influence of prior achievement and attitudes. International Journal of Science and Mathematics Education, 9(3), 691-705. http://dx.doi.org/10.1007/s10763-010-9224-5

Hulland, J. (1999). Use of partial least squares (PLS) in strategic management research: A review of four recent studies. Strategic Management Journal, 20, 195-204. http://dx.doi.org/10.1002/(SICI)1097-0266(199902)20:2<195::AID-SMJ13>3.0.CO;2-7

Ing, M., \& Nylund-Gibson, K. (2013). Linking early science and mathematics attitudes to long-term science, technology, engineering, and mathematics career attainment: latent class analysis with proximal and distal outcomes. Educational Research and Evaluation, 19(6), 510-524. http://dx.doi.org/10.1080/13803611.2013.806218

Khine, M. S., \& Afari, E. (2014). Psychometric properties of an inventory to determine the factors that affect students' attitudes toward mathematics. Psychology, Society \& Education, $6(1), 1-15$. 
Lim, S. Y., \& Chapman, E. (2013a). Development of a short form of the attitudes toward mathematics inventory. Educational Studies in Mathematics, 82(1), 145-164. http://dx.doi.org/10.1007/s10649-012-9414-x

Lim, S. Y., \& Chapman, E. (2013b). Identifying affective domains that correlate and predict mathematics performance in high-performing students in Singapore. Educational Psychology, (ahead-of-print), 1-18.

Lipnevich, A. A., MacCann, C., Krumm, S., Burrus, J., \& Roberts, R. D. (2011). Mathematics attitudes and mathematics outcomes of US and Belarusian middle school students. Journal of educational psychology, 103(1), 105-118. http://dx.doi.org/10.1037/a0021949

Lomas, G., Grootenboer, P., \& Attard, C. (2012). The affective domain and mathematics education. In Research in Mathematics Education in Australasia 2008-2011 (pp. 23-37). Sense Publishers. http://dx.doi.org/10.1007/978-94-6091-970-1_3

Ma, X., \& Kishor, N. (1997). Assessing the relationship between attitude toward mathematics and achievement in mathematics: A meta-analysis. Journal for research in mathematics education, 26-47. http://dx.doi.org/10.2307/749662

Mardia, K.V. (1970). measures of multivariate skewness and kurtosis with applications. Biometrika, 57, 519-530. http://dx.doi.org/10.1093/biomet/57.3.519

Martin, M. O., Mullis, I. V., Foy, P., \& Arora, A. (2011). Creating and Interpreting the TIMSS and PIRLS 2011 Context Questionnaire Scales. Methods and Procedures in TIMSS and PIRLS. Chestnut Hill, MA: TIMSS \& PIRLS International Study Center, Lynch School of Education, Boston College.

Mata, M. D. L., Monteiro, V., \& Peixoto, F. (2012). Attitudes towards mathematics: Effects of individual, motivational, and social support factors. Child development research, 2012, 1-10. http://dx.doi.org/10.1155/2012/876028

McDonald, R. P., \& Ho, M. R. (2002). Principles and practice in reporting structural equation analyses. Psychological Methods, 7(1), 64-82.http://dx.doi.org/10.1037/1082-989X.7.1.64

Nicolaidou, M., \& Philippou, G. (2003). Attitudes towards mathematics, self-efficacy and achievement in problem solving. In M. A. Mariotti (Ed.), European Research in Mathematics Education III (pp. 1-11). University of Pisa, Pisa, Italy.

Nunnally, J. C., \& Bernstein, I. H. (1994). Psychometric theory (3rd ed.). New York: McGraw- Hill.

Parsons, S., Croft, T., \& Harrison, M. (2009). Does students' confidence in their ability in mathematics matter? Teaching Mathematics and its Applications, 28(2), 53-68. http://dx.doi.org/10.1093/teamat/hrp010

Raykov, T., \& Marcoulides, G. A. (2008). An introduction to applied multivariate analysis. New York: Taylor and Francis. 


\section{Macrothink}

Journal of Studies in Education

ISSN 2162-6952 2015, Vol. 5, No. 2

Stankov, L., Morony, S., \& Lee, Y. P. (2014). Confidence: the best non-cognitive predictor of academic achievement. Educational Psychology, 34(1), 9-28. http://dx.doi.org/10.1080/01443410.2013.814194

Tabachnick, B. G., \& Fidell, L. S. (2007). Using multivariate statistics (5th ed.). Boston:

Pearson Education.

Zan, R., Brown, L., Evans, J., \& Hannula, M. S. (2006). Affect in mathematics education: An introduction. Educational studies in mathematics, 63(2), 113-121. http://dx.doi.org/10.1007/s10649-006-9028-2

Zan, R., \& Di Martino, P. (2007). Attitude toward mathematics: Overcoming the positive/negative dichotomy. The Montana Mathematics Enthusiast, 3, 157-168. 